\title{
Reproducibility in the Assessment of the Components of a Clinical Complexity Index
}

\author{
Marco Vincenzo Lenti, MD', Catherine Klersy, $M D^{2}$, Alice Silvia Brera, BSN' \\ Irene Benedetti, $\mathrm{MD}^{\top}$, Mariella Ciola, $\mathrm{MD}^{7}$, Giampiera Bertolino, $\mathrm{MD}^{7}$, and \\ Gino Roberto Corazza, MD ${ }^{1,3}$
}

'Department of Internal Medicine, Fondazione IRCCS Policlinico San Matteo, University of Pavia, Pavia, Italy; ${ }^{2}$ Biometry and Clinical Epidemiology, Fondazione IRCCS Policlinico San Matteo, University of Pavia, Pavia, Italy; ${ }^{3}$ Medicina Interna, Fondazione IRCCS Policlinico San Matteo, Pavia, Italy.

\author{
Abbreviations \\ $\mathrm{CC}$ \\ CI \\ ICC
}

J Gen Intern Med 34(11):2316-8

DOI: $10.1007 / \mathrm{s} 11606-019-05228-8$

() Society of General Internal Medicine 2019

\section{INTRODUCTION}

Clinical complexity (CC) represents one of the most relevant challenges of modern medicine, and its quantification is crucial both to stratify the clinical risk and for a fair hospital reimbursement policy. ${ }^{1-3} \mathrm{CC}$ is a multifaceted condition that encompasses biological (e.g., age, multimorbidity, frailty) and non-biological (e.g., socioeconomic, cultural, environmental, and behavioral) components. ${ }^{4,5}$ On this basis, a vectorial model of CC has been set up in which each vector expresses the dynamic changes over time of each component. ${ }^{5}$ Although this model cannot but be an approximation of $\mathrm{CC}$, it is able to take into account its determining factors all at once. To allow its use, each vector has been graded following a consensus meeting during which the five most representative variables of each CC domain were selected. ${ }^{6}$ However, a score made of a series of variables could be a source of variability. For this reason, we have performed an interobserver agreement study.

\section{METHODS}

In June-August 2018, three healthcare professionals conducted the present study: a senior physician (observer \#1, gastroenterology consultant), a research nurse (observer \#2), and a young physician (observer \#3, internal medicine resident). The first two observers were preliminarily trained by testing the $\mathrm{CC}$ index with roughly 100 patients, whereas only its theoretical bases were taught to the third observer. The $\mathrm{CC}$ index (Fig. 1) was administered by each observer to 30 consecutive adult patients (mean age 68 years, range $31-88$; 16 females) admitted to an academic internal medicine ward. The three observers followed a randomization list, so that each of them administered the $\mathrm{CC}$ index to the same patient for the first,

Published online August 6, 2019 second, and third times in three consecutive days. Patients with a poor prognosis $(<48 \mathrm{~h})$ were excluded. Each observer timed her/himself with an electronic chronometer during the $\mathrm{CC}$ index administration.

We rescaled each variable (Fig. 1) to have a score of 0 if the answer was "no" and a score of 2 if the answer was "yes"; these were summed up within each domain (range 0-10) and over all domains (range 0-50). Agreement of the scores computed for each domain and overall between each of the three pairs of observers was assessed with the intraclass correlation coefficient (ICC) with 95\% confidence intervals (CI). The strength of agreement was interpreted as follows: poor, < 0.50; moderate, 0.50-0.75; good, 0.75-0.90; excellent, $>0.90$.

This study represents a sub-analysis of the San MAtteo Complexity study (NCT03439410) that was approved by the local Ethics Committee.

\section{RESULTS}

Table 1 reports the results of the interobserver agreement. Overall agreement was excellent $(>0.90)$ between observers $\# 1$ and \#2, and good $(\geq 0.80)$ between observers \#1/\#2 and \#3. Domain agreement showed some weaknesses regarding the cultural domain ( $>0.50$, moderate agreement) between any two observers, and generally showed poorer results for all domains when comparing observers \#1/\#2 vs \#3. The agreement between observers \#1 and \#2 was good ( $\geq 0.80)$, particularly for the biological and socioeconomic domains.

The mean times needed to complete the CC index were 21 \pm 7 (observer \#1), $24 \pm 6$ (observer \#2), and $22 \pm 8$ min (observer \#3).

\section{DISCUSSION}

The CC index studied has a high interobserver agreement among different healthcare professionals who were trained to administer this tool (observers \#1 and \#2). Observer \#3 had a high agreement rate when considering the total $\mathrm{CC}$ index. However, the assessment of environmental and cultural domains showed lower agreement, possibly because some of their variables could be open to diverging interpretations. 


\begin{tabular}{|c|c|c|}
\hline \multicolumn{3}{|l|}{ BIOLOGICAL DOMAIN } \\
\hline Age $>75$ years & yes $\square$ & no $\square$ \\
\hline Intake $\geq 5$ medications & yes $\square$ & no $\square$ \\
\hline CIRS > 3 and/or CIRS severity $>3$ & yes $\square$ & no $\square$ \\
\hline$\uparrow$ frailty (Edmonton Frail Scale $>5$ ) & yes $\square$ & no $\square$ \\
\hline$\downarrow$ mobilization (Barthel<60) & yes $\square$ & no $\square$ \\
\hline \multicolumn{3}{|c|}{ SOCIO-ECONOMIC DOMAIN } \\
\hline Living alone & yes $\square$ & no $\square$ \\
\hline Income $<1000 € /$ month & yes $\square$ & no $\square$ \\
\hline Unemployment/precarious work & yes $\square$ & no $\square$ \\
\hline Dependent/disabled family member & yes $\square$ & no $\square$ \\
\hline Need for a caregiver & yes $\square$ & no $\square$ \\
\hline \multicolumn{3}{|l|}{ BEHAVIORAL DOMAIN } \\
\hline Inadequate adherence to medications & yes $\square$ & no $\square$ \\
\hline Active smoking of at least 4 cigarettes/day & yes $\square$ & no $\square$ \\
\hline Alcohol (>3 Alcohol Units/day) and/or drug abuse (current or past) & yes $\square$ & no $\square$ \\
\hline Inappropriate diet & yes $\square$ & no $\square$ \\
\hline Cognitive impairment (Short Blessed Test $>9$ ) & yes $\square$ & no $\square$ \\
\hline \multicolumn{3}{|c|}{ ENVIRONMENTAL DOMAIN } \\
\hline Institutionalization & yes $\square$ & no $\square$ \\
\hline Difficult access to healthcare & yes $\square$ & no $\square$ \\
\hline Presence of home architectural barriers & yes $\square$ & no $\square$ \\
\hline Occupational exposure to toxins & yes $\square$ & no $\square$ \\
\hline Air pollution & yes $\square$ & no $\square$ \\
\hline \multicolumn{3}{|l|}{ CULTURAL DOMAIN } \\
\hline Schooling $<8$ years & yes $\square$ & no $\square$ \\
\hline Insufficient access to information & yes $\square$ & no $\square$ \\
\hline Lack of adherence to health screening programs & yes $\square$ & no $\square$ \\
\hline Language barriers & yes $\square$ & no $\square$ \\
\hline Perceived discrimination & yes $\square$ & no $\square$ \\
\hline
\end{tabular}

Figure 1 Clinical complexity index assessed in the present study. The clinical complexity index was built after a consensus meeting held in 2017, involving 25 panelists ${ }^{6}$. CIRS, Cumulative Illness Rating Scale.

Table 1 Partial and Total Intraclass Correlation Coefficient Among the Three Observers for the Evaluation of an Index of Clinical Complexity. The Total Index Is Computed over 25 Items and Each Sub-domain over 5 Items

\begin{tabular}{llll}
\hline \hline & $\begin{array}{l}\text { Obs \#1 vs } \\
\text { Obs \#2 ICC } \\
\mathbf{( 9 5 \% ~ C I )}\end{array}$ & $\begin{array}{l}\text { Obs \#1 vs } \\
\text { Obs \#3 ICC } \\
\mathbf{( 9 5 \%} \mathbf{C I})\end{array}$ & $\begin{array}{l}\text { Obs \#2 vs } \\
\text { Obs \#3 ICC } \\
\mathbf{( 9 5 \%} \mathbf{C I})\end{array}$ \\
\hline Total index & $0.92(0.84-$ & $0.82(0.64-$ & $0.80(0.63-$ \\
Sub-domains & $0.96)$ & $0.91)$ & $0.90)$ \\
Biological & $0.84(0.71-$ & $0.72(0.50-$ & $0.78(0.59-$ \\
& $0.92)$ & $0.86)$ & $0.89)$ \\
Socioeconomic & $0.86(0.72-$ & $0.53(0.07-$ & $0.45(0.0-$ \\
& $0.93)$ & $0.78)$ & $0.73)$ \\
Behavioral & $0.73(0.51-$ & $0.41(0.08-$ & $0.39(0.06-$ \\
& $0.86)$ & $0.66)$ & $0.65)$ \\
Environmental & $0.73(0.47-$ & $0.39(0.04-$ & $0.34(0.0-$ \\
& $0.86)$ & $0.66)$ & $0.62)$ \\
Cultural & $0.53(0.23-$ & $0.56(0.22-$ & $0.57(0.25-$ \\
& $0.75)$ & $0.77)$ & $0.77)$ \\
\hline
\end{tabular}

CI, confidence interval; ICC, intraclass correlation coefficient; Obs, observer
Hence, a training period consisting of becoming familiar with the meaning of the variables and practicing with this tool is warranted. A larger study involving more observers is needed to confirm our findings.

The completion of the $\mathrm{CC}$ index takes approximately $20 \mathrm{~min}$, including the time needed to collect relevant patient medical history. We believe that this amount of time is acceptable, particularly in a research setting, and could be potentially reduced by computer-assisted data collection.

To conclude, the results of the present study support the feasibility of the use of the $\mathrm{CC}$ index in an internal medicine setting, and could provide background for its use in future studies. A simplification of the CC index, i.e., with fewer, but more specific, variables, will be considered at the end of its validation phase (NCT03439410).

Acknowledgements: We thank Mr. Sturgeon for having proofread the paper. 
Corresponding Author: Gino Roberto Corazza, MD; Medicina Interna, Fondazione IRCCS Policlinico San Matteo, Pavia, Italy (e-mail: gr.corazza@smatteo.pv.it).

Author Contributions All authors participated in the drafting of the manuscript or critical revision of the manuscript for important intellectual content, and provided approval of the final submitted version. Individual contributions are as follow: GRC, MVL designed the study, organized data collection, and drafted the manuscript: $M V L, A S B, I B$ conducted the study and enrolled patients; MC, GB, CK contributed to data collection and analysis; GRC made the final critical revision for important intellectual content. All authors approved the final version of the paper.

Funding This research is part of a project for the study of clinical complexity funded by San Matteo Hospital Foundation - Italian Ministry of Health (Progetto di Ricerca Corrente 2017 - PI Prof. Gino Roberto Corazza).

\section{Compliance with Ethical Standards:}

This study represents a sub-analysis of the San MAtteo Complexity study (NCTO3439410) that was approved by the local Ethics Committee.
Conflict of Interest: The authors declare that they do not have a conflict of interest.

\section{REFERENCES}

1. Whittle $\mathbf{J}$, Bosworth $\mathbf{H}$. Studying complexity is complex. J Gen Intern Med 2007:22:379-81.

2. Zullig LL, Whitson HE, Hastings SN, et al. A systematic review of conceptual frameworks of medical complexity and new model development. J Gen Intern Med 2016;31:329-37.

3. Corazza GR, Formagnana P, Lenti MV. Bringing complexity into clinical practice: An internistic approach. Eur J Intern Med 2019;61:9-14.

4. Hong CS, Atlas SJ, Ashburner JM, et al. Evaluating a model to predict primary care physician-defined complexity in a large academic primary care practice-based research network. J Gen Intern Med 2015;30:1741-7.

5. Safford MM, Allison JJ, Kiefe CI. Patient complexity: more than comorbidity. The vector model of complexity. J Gen Intern Med 2007;22:382-90.

6. Corazza GR, Klersy C, Formagnana P, Lenti MV, Padula D; Consensus Panel. A consensus for the development of a vector model to assess clinical complexity. Intern Emerg Med 2017;12:1313-8.

Publisher's Note Springer Nature remains neutral with regard to jurisdictional claims in published maps and institutional affiliations. 